\title{
Energy and Chemicals Consumption Evaluation in Water Treatment Plant A comparative study between Bacau and Turin
}

\begin{abstract}
FLORINA FABIAN ${ }^{1 *}$, VALENTIN NEDEFF ${ }^{1,2}$, NARCIS BIRSAN ${ }^{1}$, EMILIAN MOSNEGUTU ${ }^{1}$
${ }^{1}$ Vasile Alecsandri University of Bacau, Department of Environmental Engineering and Mechanical Engineering, 157 Calea Marasesti, 0600115, Bacau, Romania

${ }^{2}$ Academy of Agricultural and Forestry Sciences Gheorghe Ionescu Sisesti, 6 Marasti Blvd., 011461, Bucharest, Romania

The total energy demand of water treatment plant Bacau (WTP Bacau) was evaluated at $239.94 \mathrm{MW}$ h/y, in case of SMAT (Turin-lataly) total energy demand of the plant was evaluated at 2.235,454.9 MW h/y, and 6,9 $\%$ is for WT. Chemicals consumption, is relative and depends on raw water turbidity at WTP Bacau, during the winter period raw water is very clean and requires only a simple chlorination, on the other hand at SMAT chemicals consumption, is $5.325 \mathrm{t} / \mathrm{y}$ and $8.8 \%$ is used for water treatment process.
\end{abstract}

Keywords: water treatment, chemical consumption, energy consumption, carbon footprint

The production of drinking water from fresh surface water/groundwater involves sveral processes, energy consumption and chemical dosing, these should be considered in the choice of water treatment scheme to reduce environmental impact by applying the carbon footprintmethodology, approach require the knowledge of each equipment in water treatment plant, energy consumption, material flows.

The specific purpose of the work is to make a comparative study regarding the chemical and energy consumption at two water treatment plants respectively water treatment plant Bacau, Romania and water treatment plant SMAT Turin, Italy and to see wich have the significant impact on the environment and how can be reduce.

Water is one of the largest current and future global challenges. By 2050, world population will be increased from 7 to 9 billion. This enormous growth means that the need for water will increase by $50 \%$ if we continue to consume at the current rate (Ramboll Romania, 2012). treatment of water-varies as to the source and type of water. For example, municipal waters, consist of surface water and ground water, and their treatment is to be distinguished from that of industrial water supplies. The main objective of water treatment is to deliver good quality drinking water to consumers. Making water drinkable means removing most of the organic components, inorganic and biological components found in water, resulting water according to national and international standards concerning drinkable water [1].

\section{Water treatment plant Bacau}

Bacau City is situated in the North-Eastern part of Romania, in historical Moldova Region and has a population of 144,304 inhabitants (2011 census). WTP Bacau manages the entire water cycle in the city of Bacau and processes a maximum flow rate of $1,400 \mathrm{~m}^{3} / \mathrm{h}$ raw water from Lake Poiana Uzului [2].

Source current system of water supply for the residents of the city of Bacau consists of double supply respectively, source of surface and groundwater. Surface water source is the Poiana Uzului Lake (is not affected by industrial pollution) and source of groundwater consist from a total of six collection fronts, which include small and medium depth wells located in the riverbed of Bistrita river which are limited and do not have potential for expansion and does not,only partially ensure domestic and industrial consumption of water [2].

The main water treatment process it takes place by gravity, placing the entry point of raw water to the highest end of the plant, which will allow the water to revolve through the various treatment units, down into the treated water storage tanks, which it is approximately $9 \mathrm{~m}$ below [2].

\section{Water treatment plant SMAT, Turin}

On the other hand in case of WTP SMAT from Turin the things are different. TURIN is a important industrial city and cultural centre in northern Italy, capital of the Piedmont region, located mainly on the left bank of the Po River. With a area $130 \mathrm{Km}^{2}$ and a population of 870,702 inhabitants ( 2012 census). PO river- comes from Cotici Alps near the Italian border with French and flows into the Adriatic near Venice. Also it should be noted that the Po river is affected by the industrial pollution because it crosses Turin and other 4 cityes, (Ferrara, Piacenza, Milano, Comacchio) [3].

The SMAT SpA, Turin Metropolitan Water Company, manages the entire water cycle in the city of Turin and its province, dealing with the drinking water, the water supply and wastewater treatment. The water treatment plants are considered 3, and are as follow s: plant Po1, plant Po2, plant Po3.The first two plants came into operation as early as the first half of the '60s and possess the same technological characteristics, as well as identical potential, equal to $500 \mathrm{l} / \mathrm{s}$. The water treatment plant Po3 was designed a decade later, based on a forecast of the Plan of Aqueducts which attributed to Turin, for the year 2015, a population of 1,780,000 inhabitants: according to this projection was scheduled for Po3 a potential of $3000 \mathrm{l} / \mathrm{s}$ [3].

In systems Pol and Po2, in fact, the treatment is divided into the following phases and in the WTP Po3 the system solutions used are different, extent which creates diversity in the early stages of treatment [3].

\section{Experimental part}

The concept of carbon footprint (CF), as a fundamental quantization parameter of carbon emissions measurement, captures the interest of policy makers,

* email: florina.fabian@yahoo.com; Phone: (+40) 757728386 
businesses and consumers attention. Carbon footprint is the cumulative effect of various human activities on the environment of the Earth. It is estimated on the grounds of the methodology established by ISO 14040: 2006, Life Cycle Assessment: Principles and Framework and ISO 14044: 2006, Life Cycle Assessment: requirements and guidelines, and Publicly Available Specification (PAS 2050) [4].

Although LCA calculates the environmental impact of products or processes along its entire life cycle, it can also be used to assess only one specific stage of that life cycle, as in the present study, where only the operational stage is assessed. The functional unit is one cubic meter of drinking water produced $\left(1 \mathrm{~m}^{3}\right)$, with the quality currently delivered [4].

Two main kinds of data were used: (a) site specific data, collected from internal reports and personal interviews, and (b) data from databases included in or compatible with the used software.

The application of the methodology of the carbon footprint to water treatment processes should include the following key features [4]:

1.A clear definition for purpose of the study, of the use of the product and of the functional unit, which is composed of three parameters: amplitude (i.e. water quantity), the estimated duration of service and the expected quality level:

2.An analysis of the life cycle of the considered product, with a detailed definition of all the involved processes, is necessary to detect all direct and indirect emissions sources. The standard is explicit about this issue: $A n$ inventory consists of service, material and energy flows that become the product, make the product, and carry the product through its life cycle. These are defined as attributable processes [5]. They may be listed as follows:

- capital goods (e.g., machinery, trucks, infrastructures);

-overhead operations (e.g., facility lighting, air conditioning);

- corporate activities and services (e.g., research and development, administrative functions, company sales and marketing);
- transport of the product user to the retail location; - transport of employees to and from work.

3.An identification of materials and energy flows for the previously specified processes completes the definition of the boundaries of the analysis;

4. The first phase of data collection is a brief description of the source, of data quality and of the attempts to improve the validity of collected data;

5.A validation of the collected data by means of verification, quantification and reporting of the sources of uncertainty the considered inventory. Uncertainties may involve the parameters, the scenario and/or the model;

6.The most importantstep for applying the methodology of Carbon Footprint is computation. As it follows, we can quantify the data that we have using GWPs values provided by IPCC to turn them in the unit that interests us, namely

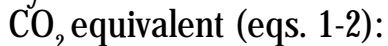

Therefore calculation of the Carbon Footprint should take into account reference flow so that the amount obtained to be fairly and justifiable (eq. 3) [5].

The total $\mathrm{CO}_{2}$ eq/unit of analysis represents the amount of $\mathrm{CO}_{2}$ equivalent $\mathrm{GHG}$ entering the atmosphere as a result of fulfilling the function of a product. Therefore, in the mass balance, emissions are treated as positive values and removals are treated as negative values. Land-use change impacts are included in the total inventory results if they are attributable to the studied product. If no land-use change impacts are attributable and no removals occur during the product's life cycle, the total inventory results are simply the sum of emissions in $\mathrm{CO}_{2}$ equivalent per reference flow.

7. At the end of the calculation and before the obtained results to be published company must obtain a certificate attesting the accuracy of the data. This step is very important because it must be in accordance with Product Standard that allows us to evaluate and interpret the results.

8. The last phase consists in achieving the final document, which will be presented to the public. The directions in terms of drafting the document are given in the Corporate Standard.

$$
\begin{aligned}
& \mathrm{kgCO}_{2} e=\text { Direct_Emissions_Data[ }[\mathrm{kgGHG}] * \mathrm{GWP}\left[\frac{\mathrm{kgCO} \mathrm{g}_{2} e}{\mathrm{kgGHG}}\right] \\
& \left.\mathrm{kgCO}_{2} e=\text { Activity_Data[2nit_of_measure }\right] * \text { Emission_Factor }\left[\frac{\mathrm{kgGHG}}{\text { 2onit_of_measure }}\right] \\
& * G W P\left[\frac{\mathrm{kgCO}_{2} e}{\mathrm{kgGHG}}\right] \\
& \frac{\text { TotalCO } \mathrm{O}_{2} e}{\text { wonit_of _onalysis }}=\frac{\mathrm{CO}_{2} e_{-} \text {Emissions }(\text { Biogenic })}{r \text { eference_flow }}-\frac{\mathrm{CO}_{2} e_{-} \mathrm{Removals}(\text { Biogenic })}{\text { reference_flow }}+ \\
& \frac{\mathrm{CO}_{2} e_{2} \text { Emission (Non-Biogenic) }}{\text { reference_flow }}-\frac{\mathrm{CO}_{2} e_{-} \mathrm{Re} \text { movals (Non-Biogenic) }}{\text { reference_flow }} \\
& +\frac{\mathrm{CO}_{2} e_{-} \text {Land_Use_Change_Im pact }_{\text {I }}}{\text { reference_flow }}
\end{aligned}
$$

\section{Results and discussions}

Energy consumption for drinking water production at WTP Bacau. Energy is usually required for extracting raw water from either source. Some water sources need very little treatment, so their energy intensity is low as is the case of WTP Bacau. Groundwater extraction requires approximately $30 \%$ more electricity on a unit basis than surface water extraction. Different factors such as the distance from the water source to the consumer, water abundance, initial quality, and required treatment for use determine the overall energy expenditure per volume unit of water [6-10].

WTP Bacau consumed an amount of electricity, which in 2015 was equal to $239.94 \mathrm{MW} \mathrm{h/y} \mathrm{(table} \mathrm{1).} \mathrm{The}$ connection of equipment from the WTP Bacau at the electrical power supply is made at town network. In the urban water cycle, water supply, transportation, treatment and disposal are services that consume a considerable amount of energy. In this stage electricity is the main energy source. In addition, there is an indirect energy use for the production of chemicals. 


\begin{tabular}{|c|c|c|c|c|c|}
\hline Item & Description & kWh/day & kWh/month & kWh/y & MWh/y \\
\hline MCC 101 & $\begin{array}{c}\text { Inlet Works and } \\
\text { Clarifier }\end{array}$ & 29.92 & 897.6 & $10,771.2$ & 10.77 \\
\hline MCC 102 & Filtration & 139.25 & $4,177.5$ & 50,130 & 50.13 \\
\hline MCC 103 & Chlorination & 92.75 & $2,782.5$ & 33,390 & 33.39 \\
\hline MCC 104 & Chemicals & 134.67 & $4,040.1$ & $48,481.2$ & 48.48 \\
\hline 105 & Technical Building & 269.93 & $8,097.9$ & $97,174.8$ & 97.17 \\
\hline TOTAL POWER MWh/year & \multicolumn{4}{|c|}{$\mathbf{2 3 9 . 9 4}$} \\
\hline
\end{tabular}

Table 1

W ATER TREATMENT

PLANT BACAU - ENERGY

CONSUMPTION
The embodied energy associated with raw water extraction is unique to every water system, ranging from the low energy requirements of an unfiltered gravity-fed system to the high energy requirements of a pumped seawater reverse osmosis system.

As can be seen (fig. 1), in the case of WTP Bacau in water treatment process the highest energy consumption per year is registered by the Technical Building which is $40 \%$ from total energy consumption and includes Circulation Pump 1, Circulation Pump 2, Laboratory Equipment, $p H \&$ Conductivity Meter Water Analyzer Group 1 and 2, Chlorine Contact Tank Sample Water Selenoid Valve etc.

Chemical consumption for drinking water production at WTP Bacau

The production of drinking water from fresh surface water involves several processes, energy consumption and chemical dosing, all having global environmental impacts.

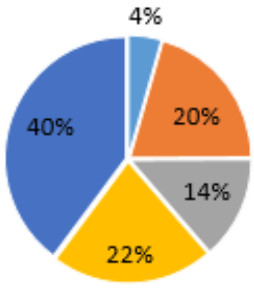

$$
\begin{aligned}
& \text { MCC } 101 \text { Inlet Works and } \\
& \text { Clarifier } \\
& \text { MCC } 102 \text { Filtration } \\
& \text { MCC } 103 \text { Chlorination } \\
& \text { MCC } 104 \text { Chemicals }
\end{aligned}
$$

Fig 1. Energy consumption for water tretment process Bacau

These should be considered in the choice of water treatment processes, and in the same time drawing attention to the importance of the choice of water treatment chemicals (table 2) and energy source.

In general for the chemical treatment of water is used a great variety of chemicals, in our case at WTP Bacau, we

\begin{tabular}{|c|c|c|c|c|c|}
\hline $\begin{array}{c}\text { Chemical } \\
\text { Consumption } \\
\text { WTP Bacau }\end{array}$ & $\begin{array}{l}\text { Unit cost, } \\
\text { EUR/kg }\end{array}$ & $\begin{array}{c}\text { Average effective } \\
\text { flow, } \\
\mathrm{m}^{3} / \mathrm{day} \\
60,000 \mathrm{~m}^{3} / \text { day }\end{array}$ & $\begin{array}{c}\text { Guaranteed } \\
\text { chemical doze, } \\
\mathrm{kg} / \mathrm{m}^{3}\end{array}$ & $\begin{array}{l}\text { Guaranteed unit } \\
\text { chemical cost, } \\
\text { EUR/m }{ }^{3}\end{array}$ & $\begin{array}{c}\text { Guaranteed } \\
\text { annual } \\
\text { chemical cost, } \\
\text { EUR/y }\end{array}$ \\
\hline \multirow[t]{2}{*}{1} & 2 & 3 & 4 & 5 & 6 \\
\hline & & & & $\operatorname{col} 12 \times \operatorname{col} 14$ & $\begin{array}{c}\operatorname{col} 3 x \operatorname{col} 5 x \\
365 \mathrm{~d}\end{array}$ \\
\hline \multicolumn{6}{|l|}{$\begin{array}{l}\text { Raw water } \\
\text { NTU } 1 \text { - } 10\end{array}$} \\
\hline Alum & 0.16 & 30,000 & 0.04 & 0.0064 & 70,080 \\
\hline Lime & 0.08 & 30,000 & 0.02 & 0.0016 & 17,520 \\
\hline PAC & 1.25 & 30,000 & & & \\
\hline Polymer & 3.5 & 16,800 & 0.00015 & 0.000525 & $5,748.75$ \\
\hline $\mathrm{CI} 2$ & 0.28 & 30,000 & 0.0015 & 0.00042 & 4,599 \\
\hline \multicolumn{6}{|l|}{$\begin{array}{c}\text { Raw water } \\
\text { NTU } 10 \text { - } 20\end{array}$} \\
\hline Alum & 0.16 & 21,000 & 0.04 & 0.0064 & 49,056 \\
\hline Lime & 0.08 & 21,000 & 0.02 & 0.0016 & 12,264 \\
\hline PAC & 1.25 & 21,000 & & & \\
\hline Polymer & 3.5 & 21,000 & 0.00015 & 0.000525 & $4,024.13$ \\
\hline $\mathrm{Cl2}$ & 0.28 & 21,000 & 0.0015 & 0.00042 & $3,219.3$ \\
\hline \multicolumn{6}{|l|}{$\begin{array}{l}\text { Raw water } \\
\text { NTU } 20-70\end{array}$} \\
\hline Alum & 0.16 & 9,000 & 0.05 & 0.008 & 26,280 \\
\hline Lime & 0.08 & 9,000 & 0.03 & 0.0024 & 7,884 \\
\hline PAC & 1.25 & 9,000 & 0.01 & 0.0125 & $41,062.5$ \\
\hline Polymer & 3.5 & 9,000 & 0.0002 & 0.0007 & $2,299.5$ \\
\hline $\mathrm{CI2}$ & 0.28 & 9,000 & 0.0015 & 0.00042 & $1,379.7$ \\
\hline $\mathrm{NaOH}$ & 0.25 & & & & 500 \\
\hline Total & & & & & $245,96.88$ \\
\hline
\end{tabular}
have Chlorine ( 9.6 t/year), Aluminum sulfate (360 t/year), Polymer ( 3 t/year). I must to specify that the quantity of

Tabel 2

WATER TREATMENT PLANT BACAU -CHEMICAL CONSUMPTION 
chemicals used in water treatment (fig. 2) at WTP Bacau is relative and depends on raw water turbidity (minimum $5 \mathrm{NTU}$ ), for example during the winter period raw water is very clean in view point of physico-chemical characteristics and requires only a simple chlorination.

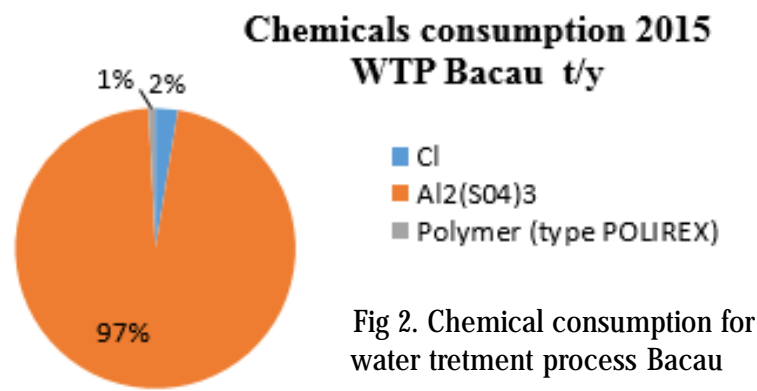

\section{Energy consumption for drinking water production atSMAT Turin}

According to data released bySMAT, power consumption for plantservices account for $1.1 \%$ of the global. Such figure can be compared with the amount of water taken up, according to the Declaration Annual volumes of derivatives from Surface Waters published by Smart in 2016. The collected data are summarized to provide an overview in table 3 [11].

The calculation of the electricity used ( fig.3) is simplified by the presence of such a work, an energy meter arranged by the company responsible for the supply.

\section{Energy consumption [kWh/year (2015)]}

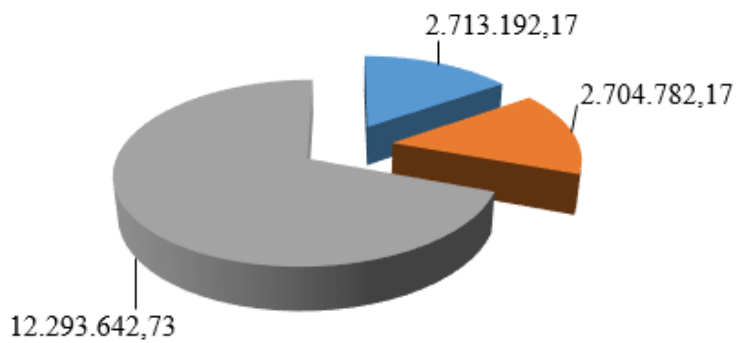

$\sim$ Po1

$\because$ Po2

$\because \mathrm{Po} 3$

Fig 3. Energy consumption for water treatment Po1-2-3 SMAT Turin

As we cant observe in table 4 the energy consumption is divided in 5 parts and consists essentially in: extraction of raw water, accumulation and lifting, potabilization, distribution, services. The biggest part is consumed in proces extraction of raw water and it's approximately 54.9 $\%$ from the total quantity.

Chemical consumption for drinking water production at SMATTurin

Already in the 90 SMAT he had embarked on a program to reduce the use of chemical reagents (table 5) used in water purification through the optimization of processes
Table 3

ENERGY CONSUMPTION - WTP SMAT 2015

\begin{tabular}{|c|c|c|}
\hline Operation & $\begin{array}{c}\text { Energy } \\
\text { consumption } \\
{[\mathrm{kWh} / \text { year }]}\end{array}$ & $\begin{array}{c}\text { Energy } \\
\text { consumption } \\
\text { MWh/year }\end{array}$ \\
\hline \multicolumn{3}{|l|}{ Pol } \\
\hline Clarification & $128,617.17$ & $12,861.717$ \\
\hline Filtration & $36,495.00$ & $3,649.5$ \\
\hline Second lifting & $2.350,080.00$ & 235,008 \\
\hline Drain sludge & $198,000.00$ & 19,800 \\
\hline Total & $2.713,192.17$ & $271,319.217$ \\
\hline \multicolumn{3}{|l|}{ Po2 } \\
\hline Clarification & $128,617.17$ & $12,861.717$ \\
\hline Filtration & $29,568.00$ & $2,956.8$ \\
\hline Second lifting & $2.348,597.00$ & $234,859.7$ \\
\hline Drain sludge & $198,000.00$ & 19,800 \\
\hline Total & $2.704,782.17$ & $270,478.217$ \\
\hline \multicolumn{3}{|l|}{ Po3 } \\
\hline Oxidation & $1.424,284.00$ & $142,428.4$ \\
\hline Clarification & $795,495.60$ & $79,549.56$ \\
\hline Filtration & $239,987.50$ & $23,998.75$ \\
\hline Second lifting & $9.258,635.63$ & $925,863.563$ \\
\hline Drain sludge & $575,240.00$ & 57,524 \\
\hline Total & $12.293 .642,73$ & $1.229,364.2$ \\
\hline Totale Pol-Po2 & $5.417,974.34$ & $541,797,4$ \\
\hline Total plant $\mathrm{Po}_{0}$ & $22.354,549.21$ & $2.235,454.9$ \\
\hline Total bill & $18.151,636.00$ & $1.815,163.6$ \\
\hline $\begin{array}{l}\text { Percentage } \\
\text { difference }\end{array}$ & $23 \%$ & $23 \%$ \\
\hline
\end{tabular}

(for example by automatic controls kind of 'feedback' and feed-forward) and the adoption of environmentally friendly technologies (activated carbon, Organic, ultraviolet rays, etc.). Thanks to these improvement activities it can be stated that the use of chemicals in the treatment of water intended for human consumption it has been optimized at the lowest extent possible consistent with the need to ensure the sanitary quality of the water produced [11].

It should also be remembered that variations in the consumption of some reagents (fig.4), also up to $10-20 \%$, can be considered physiological because conditioned by climatic events that have occurred during this reporting period; For example, heavy rainfall may also require increases up to 4-5 times the average dose the flocculant used (aluminum polychloride) [12].

\begin{tabular}{|l|c|c|c|c|c|}
\hline Energy consumption \% & $\mathbf{2 0 1 1}$ & $\mathbf{2 0 1 2}$ & $\mathbf{2 0 1 3}$ & $\mathbf{2 0 1 4}$ & $\mathbf{2 0 1 5}$ \\
\hline Extraction of raw water & 49.9 & 55.4 & 54.9 & 55.8 & 52.8 \\
\hline Accumulation and lifting & 41.0 & 36.5 & 36.5 & 35.4 & 37.5 \\
\hline Potabilization & 6.9 & 6.0 & 5.9 & 6.4 & 6.9 \\
\hline Distribution & 1.1 & 1.2 & 1.2 & 1.0 & 1.7 \\
\hline Services & 1.1 & 0.9 & 1.5 & 1.4 & 1.1 \\
\hline
\end{tabular}

Table 4

ENERGY CONSUMPTION FOR WATER TREATMENT PROCESS - WTP SMAT 


\begin{tabular}{|l|r|r|r|r|r|}
\hline Reagent (Tons) & $\mathbf{2 0 1 1}$ & $\mathbf{2 0 1 2}$ & $\mathbf{2 0 1 3}$ & $\mathbf{2 0 1 4}$ & $\mathbf{2 0 1 5}$ \\
\hline Sodium hypochlorite & 1,357 & 1,452 & 1,423 & 1,589 & 1,493 \\
\hline Hydrochloric acid & 182 & 182 & 177 & 156 & 167 \\
\hline Sodium chlorite & 225 & 206 & 217 & 206 & 200 \\
\hline Aluminum chloride & 2,878 & 2,742 & 2,769 & 2,542 & 2,456 \\
\hline Silica & 41 & 35 & 19 & 53 & 35 \\
\hline Granular sea salt & 356 & 274 & 331 & 218 & 186 \\
\hline Activated carbon reactivated & 488 & 439 & 489 & 468 & 492 \\
\hline New activated carbon & 126 & 116 & 127 & 145 & 121 \\
\hline Ferric chloride & 133 & 41 & 9 & 7 & 8 \\
\hline Carbon dioxide & 104 & 123 & 144 & 157 & 127 \\
\hline Sodium hydroxide & 14 & 11 & 6 & 8 & 7 \\
\hline Qther reagents & - & - & - & 21 & 33 \\
\hline Total & 5.904 & 5.621 & 5.711 & 5.570 & 5.325 \\
\hline
\end{tabular}

Table 5

CHEMICAL CONSUMPTION - WTP SMAT

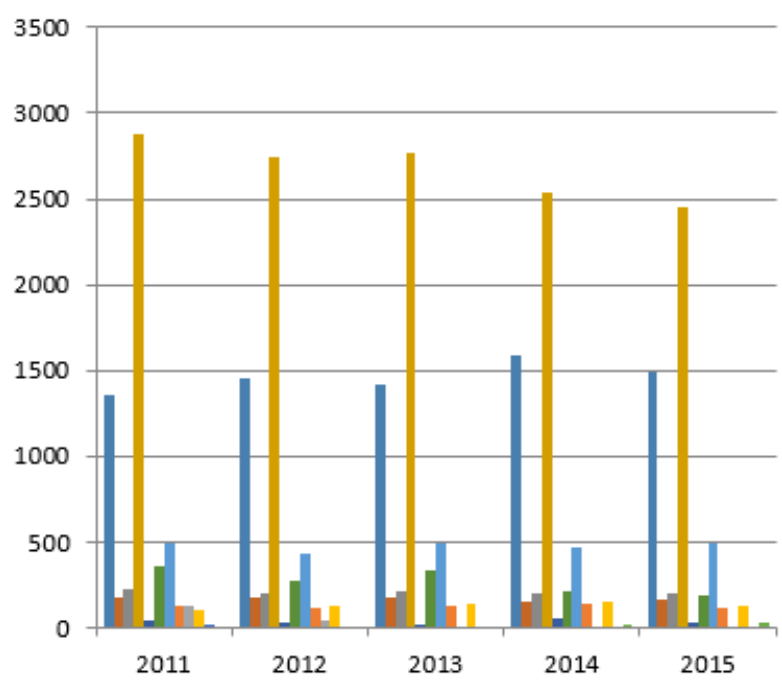

\section{Conclusions}

The traditional tool of evaluation of water treatment plants in terms of efficiency in removal of critical parameters and of cost for operative activities must be today integrated with a verification of total compatibility of the operation [14]; in account of the large effect of this aspect; in particular the capacity to generate GHG from energy use and from chemicals transport and utilization must be carefully considered.

The main objective of this paper was to compare the environmental impacts between two water treatment plant one from Romania and one from Italy by using carbon footprint methodology (CF) from a practical and applicability point of view in order to support various water management stakeholders and especially the water treatment operators.

For this purpose, this study has been developed around a tow case studies (Bacau and Turin) to enable comparison of water treatment processes, the amount of chemical and energy used for water treatment processes. The two water treatment plants presentrather different approaches to environmental impact definition and quantification due to water treatment process as it was presented in the overview of WTP.

Although the two water treatment plants have different principles for environmental impact quantification, the results have shown differences regarding de energy consumption and quantity of chemical consumption because of the fact that two water treatment plants are very different in point of view of flow rate, number of inhabitants, source of water and we must consider that
- Sodium hypochlorite

- Hydrochloric acid

- Sodium chlorite

Aluminum chloride

- Silica

Granular sea salt

activated carbon reactivated

Fig 4. The process of water treatment Po1-2-3 SMAT Turin

New activated carbon

Ferric chloride

Carbon dioxide

Sodium hydroxide

Other reagents

the source of water in Turin, Po river is affected by industrial poluttion while in Bacau source of water Poiana Uzului Lake is not affected by industrial poluttion but another aspect that I must specify is the difference between water treatment schems.

However, the analysis of results has demonstrated the weak and strong points of each water tretment plant and has emphasized the necessity for improving the weak points. For example in the case of WTP Bacau the quality of water wich reaches the consumer undergoes changes because of outdated water supply system, in this case measures to be taken reffers to renovation of distribution network, operation wich started from last year. Furthermore, the resultanalysis and discussion pointed out that at least for two stakeholders involved in water management (water operator and management authority).

Concerning the priorities of the Romanian and European research programs, the environmental problems, the sustainable management of natural resources and carbon footprints as an environmental objective in addition to the economic efficiencies when identifying the optimal water supply expansion strategies subject to technical, managerial, and social remain key issues for Romania's development [15].

Acknowledgements : The SMAT - Società Metropolitana Acque Torino S.p.A water treatment plant from Turin.

\section{References}

1. MERENDA A., Application of Carbon Footprint to drinking water treatment, (in Italian), MSc Thesis, Politecnico di Torino, Italy, 2012. 
2. *** ENVIRONMENTAL PROTECTION BACAU AGENCY, The EnvironmentAgreement for the construction of ww ater treatment plant Bacau, Bacau, 2007.

3. MASSARUTTO A., MUSOLINO D., Drought management in a wide, densely populated and highlygdeveloped area, Po River Basin, Italy, University Milano, 2010.

4. BARRIOS R., SIEBEL M., HELM A., BOSKLOPPER K., GII ZEN H. Environmental and financial life cycle impact assessment of drinking water production at Waternet, J ournal of Cleaner Production, Amsterdam, Netherlands, vol. 16, p 471-476, 2008.

5. SHRESTHA E., SAJJAD A., JOHNSON W., BATISTA J.R., The carbon footprint of water management policy options, Energy Policy, vol. 42, p 201-212, 2012.

6. *** EUROPEAN COMMISION Water scarcity and droughts in the European Union, August 2010. Available at: http://ec.europa.eu/ environment/pubs/pdf/factsheets/water_scarcity/it.pdf, (accessed on 27/6/2016).

7. IGOS E., BENETTO E., BAUDIN I., TIRUTA-BARNA L., MERY Y., ARBAULT D., Cost-performance indicator for comparative environmental assessment of water treatment plants, Science of the Total Environment, 443, 367-374, 2013.

8. BONTON A., BOUCHARD C., BARBEAU B., JEDRZEJAK S., Comparative life cycle assessment of water treatment plants, Desalination, 284, 42-45, 2012.
9. LEMOS D., DIAS A.C., GABARRELL X., ARROJA L., Environmental assessment of an urban water system, Journal of Cleaner Production, 54, 157-165, 2013.

10. LUNDIE S., PETERS G., BEAVISP C., Life Cycle Assessment for Sustainable Metropolitan Water Systems Planning, Environmental Science\&Technology, 38, 3465-3473, 2004.

11.VENKATESH G., BRATTEB H., Energy consumption, costs and environmental impacts for urban water cycle services: Case study of Oslo (Norway), Energy, 36, 792-800, 2011.

12.*** SOCIETA METROPOLITANA AQUE TORINO, BILANCIO DI SOSTENIBILITA TURIN, Italy 2015, available at: $h$ ttp://www.smatorino.it/ documenti/area_istituzionale/BILANCIO-Di-SOSTENIBILITA-SMAT2015.pdf

13. BOTTO S., NICCOLUCCI V., RUGANI B., NICOLARDI V., BASTIANONI S., GAGGI C., Towards lower carbon footprint patterns of consumption: The case of drinking water in Italy, Environmental Science\&Policy, vol.14, p 388-395, 2011.

14. CARABET, B., FLORESCU, C., STANILOIU, C., PODOLEANU, C., VISESCU, M., BELU, M., ILIE, C., The Eficiency of Resita Town Water Treatment Plant,Rev. Chim. (Bucharest), 64, no. 5, 2013.

15. CIRTINA, D., CAPATINA, C., Assessment of Tismana Downstream Storage Reservoir Ecological Potential by Water Quality Monitoring, Rev. Chim. (Bucharest), 67, no.9, 2016.

Manuscript received: 2.02 .2018 